\title{
Construction Method Selection and Simulation
}

\author{
Slab Construction Method Case Study
}

\author{
HIROSHI TABAI YOSHIKAZUSASAKI YOUICHI YUASA \\ Takenaka Research \& Development Institute
}

\begin{abstract}
In Construction Planning, it is necessary to select the most suitable construction method for the requirements of the design. However, as information on the construction method chiefly depends on individual experience, the construction method might not have always been selected properly. In this paper, the overall concept of the Construction Method Selection Support System required for the Construction Method Planning was described. On the basis of the above concept, the Slab Construction Method Selection Support System was actually developed. The System was fully verified the System provides valuable support for improving the Construction Method Planning and eliminating or reducing time and labor.
\end{abstract}

\section{Introduction}

Various construction methods have been developed to minimize construction costs and duration. Some of them have been put to practical use. In Construction Planning, it is necessary to select the most suitable construction method for the requirements of the design. However, as information on the construction method chiefly depends on individual experience the construction method might not have always been selected properly. This paper will where the Construction Method Planning is positioned within in the whole Construction Planning. The overall concept of the Construction Method Selection Support System required for the Construction Method Planning is also described. The Slab Construction Method Selection Support System developed on the basis of the overall concept is detailed.

\section{Positioning of Construction Method Planning within Construction Planning}

As shown in Fig. 1, the Building Construction Process may be classified into two major categories: design and construction planning and management. Construction Planning may further be classified generally into three elements; viz., Construction Method Planning, Transportation Planning, and Process Planning. All of the planning will be 
carried out to satisfy the conditions of construction duration, cost, quality, safety, and environment on the basis of the design requirements. Above all, the Construction Method Planning is positioned as a bridge between design and construction stages, which are separated from each other in terms of the systematic process, and Construction Method Planning plays an important part in the process. Each of the three elemental forms of planning within Construction Planning is discussed below.

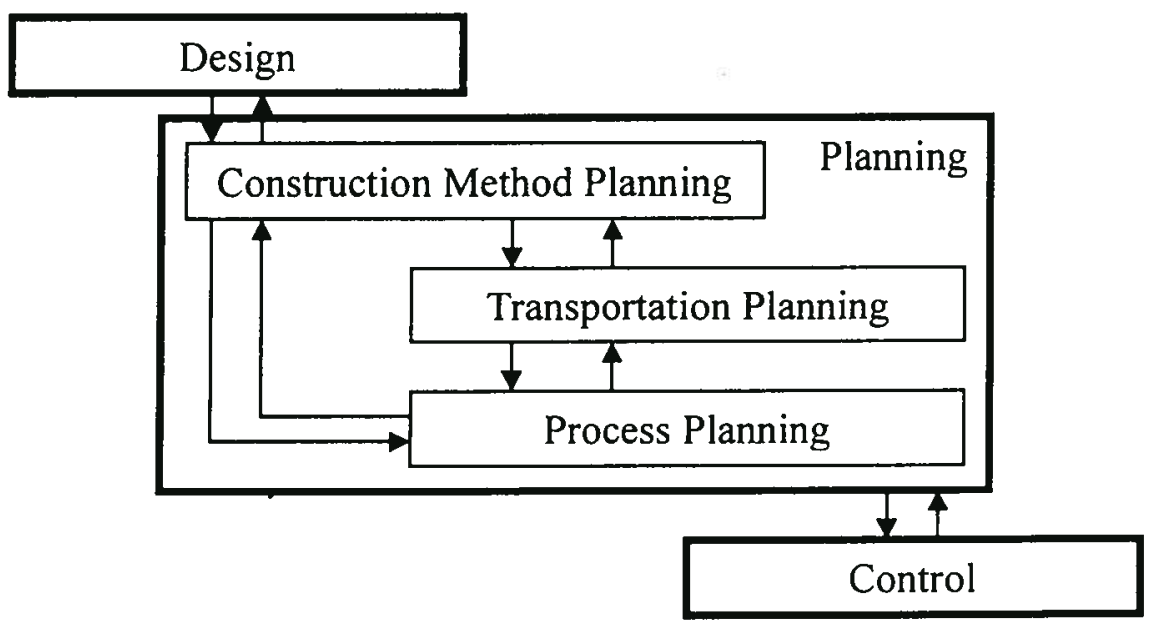

Figure 1. Positioning of Construction Method Planning within Construction Planning

\subsection{CONSTRUCTION METHOD PLANNING}

To date various construction methods with distinctive features, such as the precast construction method, have been used in projects. In Construction Method Planning, a Construction Planner applies such construction methods to building elements in accordance with the design requirements and combines these construction methods consistently with each other. As a result of an evaluation of construction methods chiefly from the viewpoint of construction cost and duration, the most suitable construction method is selected. However, it should be noted that if Construction Method Planning is only a one-way planning process, separated and independent from design, the Construction Method Planning would serve little purpose. Rather, the twoway, or reciprocal borderless planning process will prove much more fruitful, such as design by a designer in consideration of construction or VE(Value Engineering) proposals to the designer by the Construction Planner.

\subsection{TRANSPORTATION PLANNING}

In building construction, the propriety of Transportation Planning has a great influence on the overall planning of a project. Transportation Planning features timely transport of necessary construction materials, temporary materials and workers to designated work places in accordance with Process Planning, with the Construction Planner classifying them and examining the suitable timing and volume of transportation and the type and number of transportation equipment. It is noted that not only constituent elements of 
transportation, but also relevant building construction methods are examined in Transportation Planning. This is because construction methods are examined when planning the partitioning of members to determine whether or not the Precast method is to be adopted.

\subsection{PROCESS PLANNING}

In the Process Planning, the Construction Planner plans the distribution of resources, the work sequence, and the working days required in accordance with the Construction Method Planning. The construction process is determined along with the construction method. Both the proposed construction process and methods are reciprocally checked whenever the occasion arises. Consequently, a plan is prepared for the construction process. Generally, the Construction Duration is frequently used a major factor in evaluating the proposed construction methods.

\section{Overall Conception of the Construction Method Selection Support System}

\subsection{COMPOSITION OF THE SYSTEM}

The general view of the Support System necessary for the Construction Method Planning is as shown in Fig. 2. This System is composed of two factors: the simulation factor that calculates construction cost and duration by selecting and combining the elements of the construction methods and the data base factor that stores both technical knowledge on each construction method and information on the construction cost required for the simulation. Using the System, the Construction Planner selects the most suitable Construction Method.

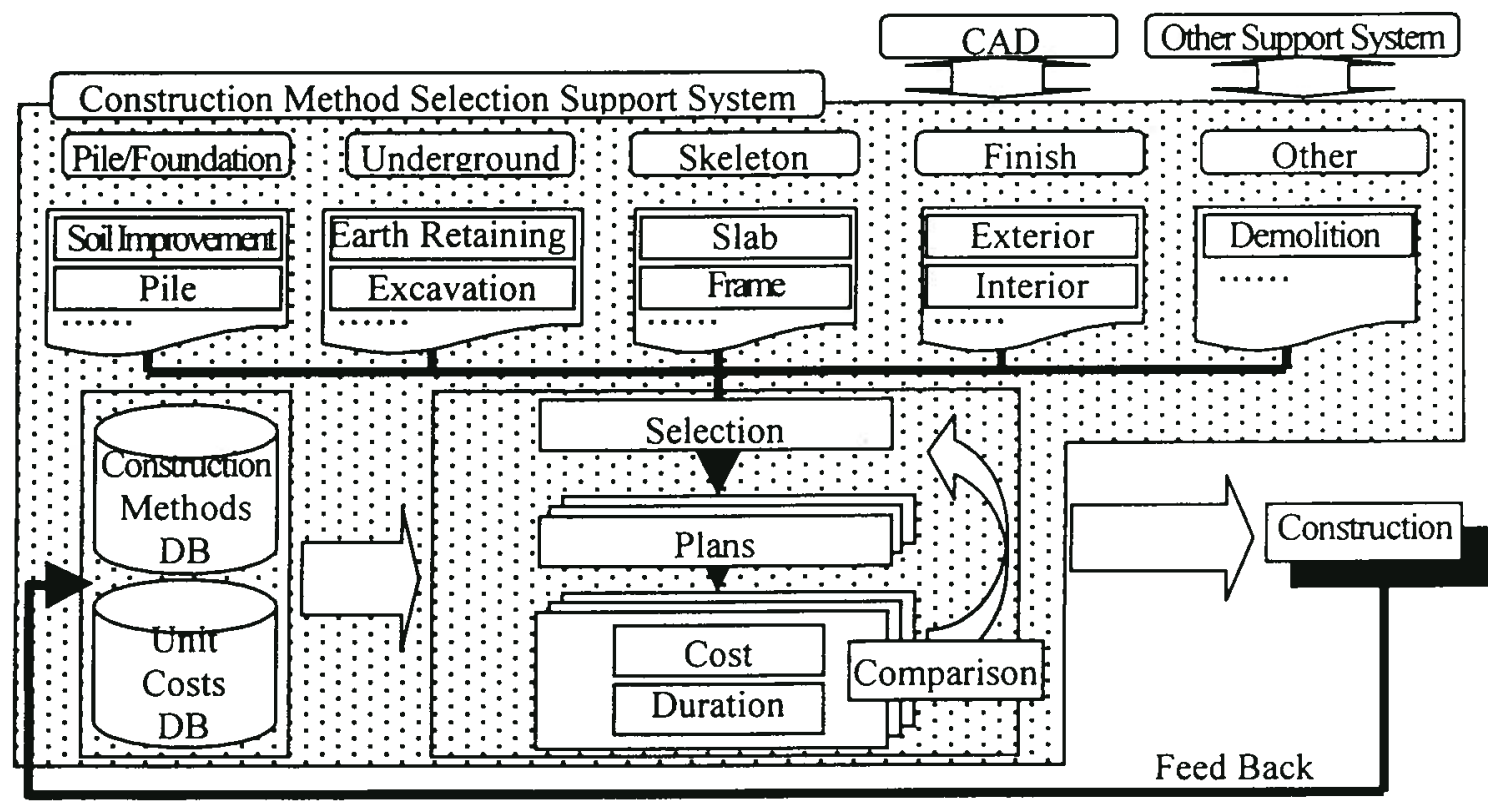

Figure2. General View of Construction Method Selection Support System 


\subsection{BASIC FUNCTIONS OF THE SYSTEM}

The basic functions required for the Construction Method Selection Support System are described below.

\subsubsection{Building a Data Base of Up-to-date Information on Construction Methods and Costs}

Various featured construction methods have been applied in increasing numbers. In addition, the unit costs of materials, equipment, and labor necessary for evaluating the cost of the construction methods vary by locality and time. Therefore, it is expected that by building a data base of up-to-date information on these unit costs, such construction methods and unit costs may be examined and compared with each other, satisfying the above conditions and complying with the actual circumstances. The database has information on construction methods and unit costs which may be updated with ease at any time.

\subsubsection{Selection of Construction Methods under Given Conditions}

Various conditions are attached to the proposed construction methods. Some conditions relate to design requirements such as the use of buildings and structure types. Some relate to the compatibility of construction methods for other building elements. It is very difficult for a Construction Planner to select the most suitable construction method from among various proposed construction methods in compliance with these conditions. This System informs the Construction Planner whether or not each proposed construction method is applicable under the design requirements. As a result, the Construction Planner can make a more effective plan.

\subsubsection{Examination of Construction Methods Using a Simulation Technique}

Indeed, the most suitable construction method may be automatically selected by a computer with a standard logic. However, each project has its own features which will require the Construction Planner to come up with various ideas to make a suitable plan. It very difficult for this technique to meet needs of the Construction Planner. Thus, a simulation technique is adopted in this System. Such a System enables the Construction Planner to proceed with the examination of the proposed construction methods by verifying the steps in the examining process. He can also finally evaluate the construction methods on the basis of the output results of the examination of construction cost and duration.

\subsubsection{Selection of Construction Method Reflecting Actual Results}

When a Construction Planner with less practical experience plans construction methods, he often makes a less accurate plan and takes more time than a Construction Planner with more experience. This System makes it possible for a more accurate plan to be made by feeding back information to the next plan construction results and information on each project accumulated in the database.

\section{Case of Slab Construction Method Selection Support System}

\subsection{PURPOSE OF DEVELOPMENT AND COMPOSITION OF SYSTEM}


As the cost of slabs has a great influence on construction cost, slab are taken up as an example to develop the Support System. The purpose of the System is to make it possible to promptly support any VE proposals given to the design section in the construction stage, and enable production design to take into consideration construction cost and workability in Design and Build. Although this System has been developed on the basis of the overall concept of the Construction Method Selection Support System, the former system differs from the latter chiefly in the following respects:

1)The Construction Duration is not taken into account when evaluating the construction methods. The Construction Duration is greatly affected by other elements, such as the performance of cranes, construction yardstick, etc., than the slab construction methods. Thus, it is not possible to calculate Construction Duration accurately using the construction methods alone.

2)A slab equivalent to the length of one bay ( 1 span $\times 1$ span) and beams are the subjects of examination. The Construction Planner finally evaluates the total building by converting the results of the examination of the one bay long slab into the total building.

This System consists of a simulation system and a maintenance system: The simulation system calculates construction cost by combining selected elements of construction methods. The maintenance system is simplified using technical knowledge on construction methods and information on cost saving in the database. The content of each system is as described below:

\subsection{SIMULATION SYSTEM}

Some applicable construction methods are showed under the project conditions. Then, from among the showed construction methods some construction methods are further selected as proposed methods. The Simulation System enables construction costs to be compared by making an automatic structural and execution quantity calculation for each proposed construction method. The flow of the System is shown in Fig. 3.

\subsubsection{Establishment of Requirements} of Slab Design

Design requirements are made to a slab of one bay length as in Fig. 4 and Fig. 5. Here, such requirements as use of rooms, length of span, floors, thickness of slab, height of floor, information relating to concrete, load

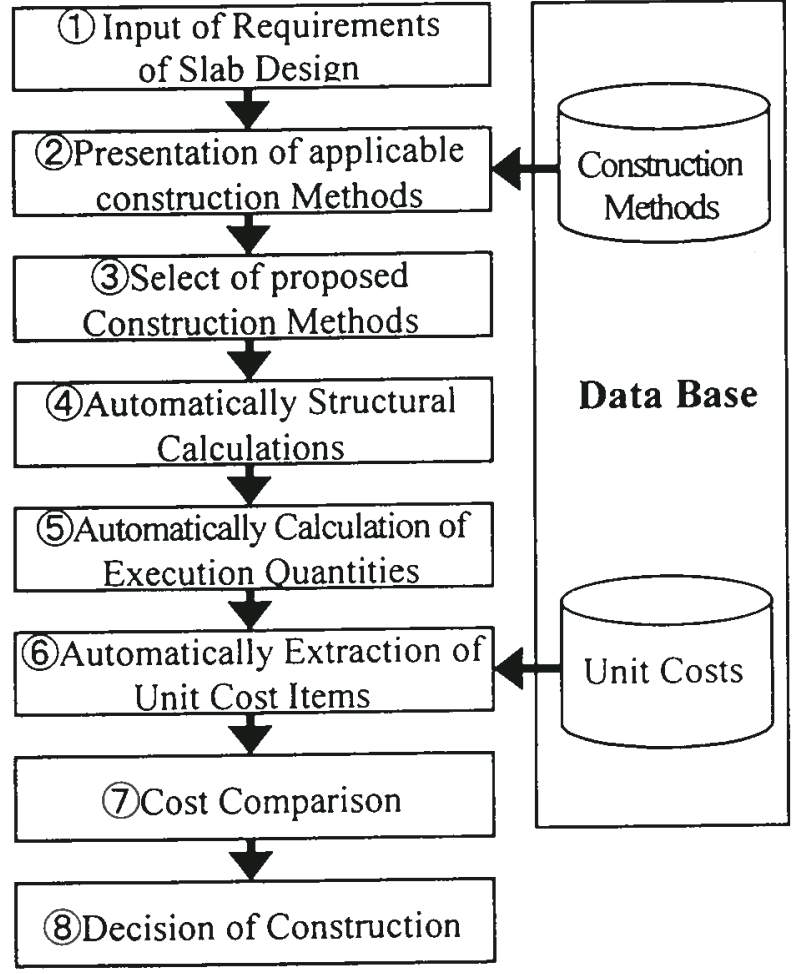

Figure3. The flow of the System 
and deflection conditions, and fire resistive conditions are saved in the System. As these requirements have a default value in the use of each room, a hypothetical design may be worked out using the default values at the initial design stage when the design requirements are not yet decided. Then, the default values are changed consistent with the project, which will be examined as the design progresses.

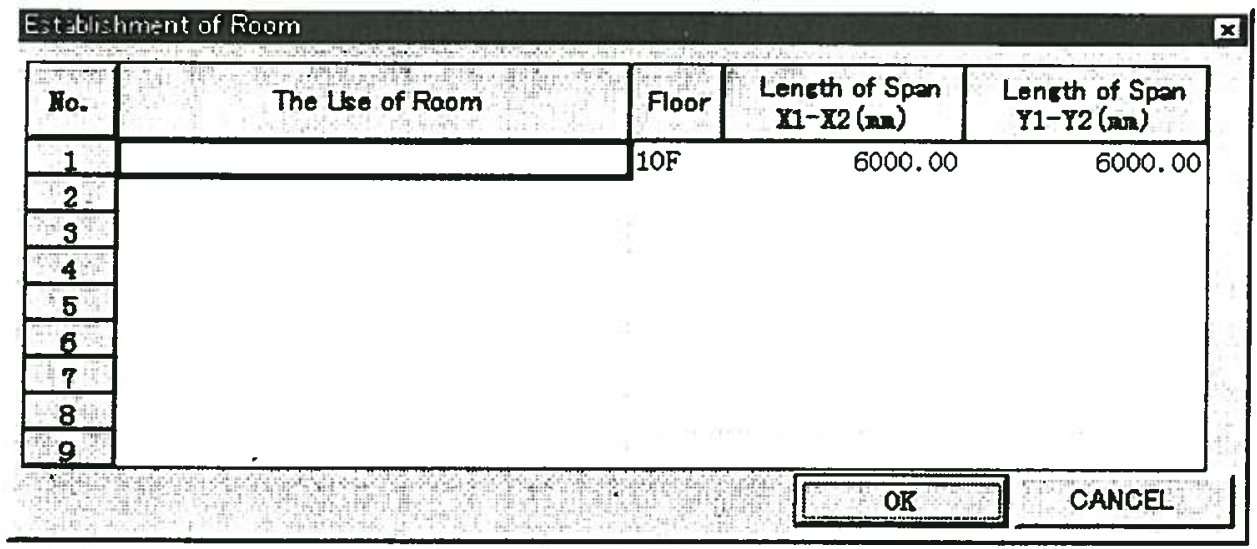

Figure4. The Screen of Established of Room

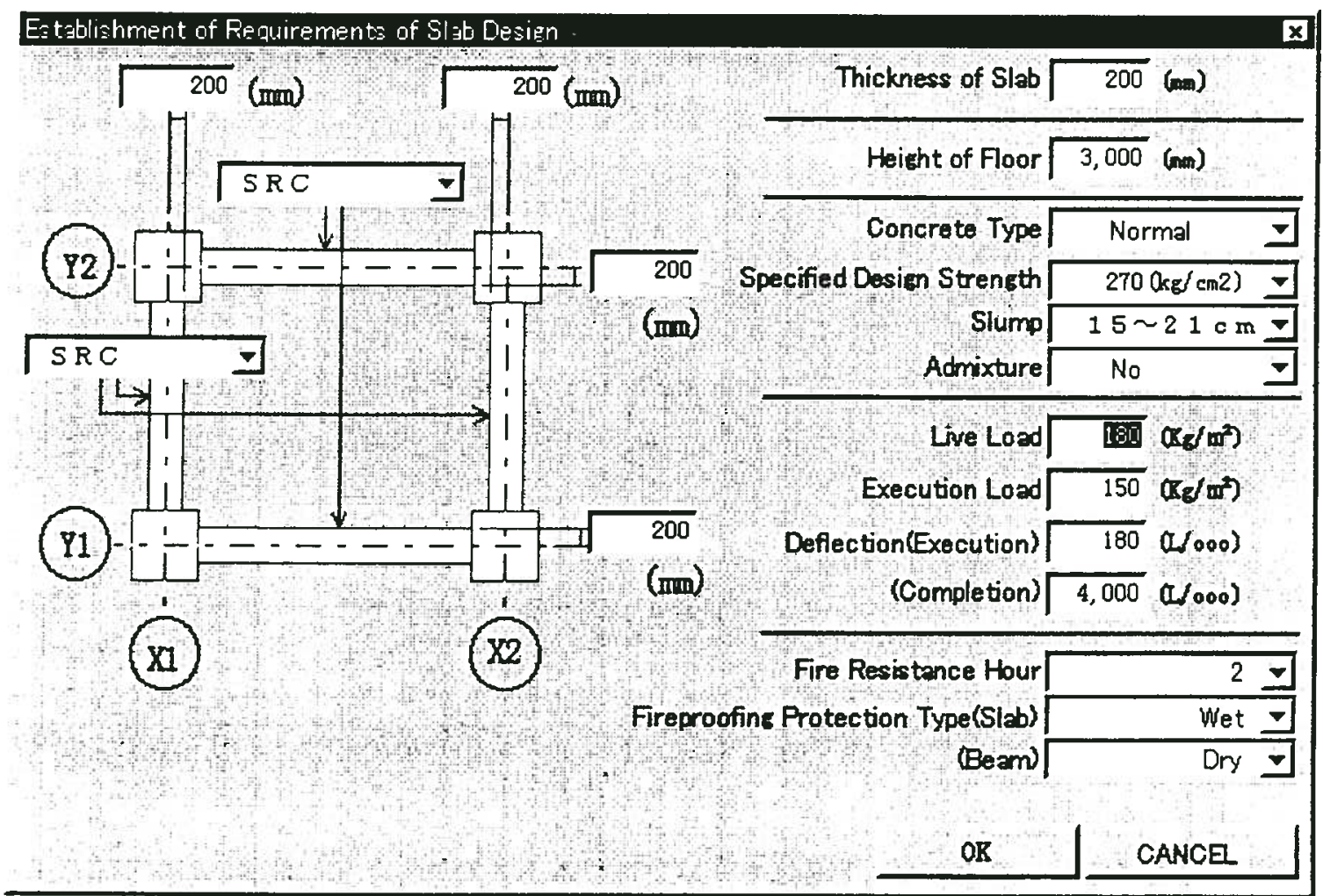

Figure5. The Screen of Establishment of Slab Design Requirements 


\subsubsection{Selection of the Slab Construction Methods}

To date, many slab construction methods have been used in projects, and it is very difficult to compare one with others on a common basis. Forty Slab construction methods are saved in this system. Applicability tests are carried out on each method saved, giving such grades as $\bigcirc$ (stands for "suitable"), $\triangle$ ("applicable") or $X$ ("further examination required"). On the screen shown in Fig. 6, the Construction Planner may confirm the results of such a judgment. The judgment is made on the basis of specified values for the use of rooms, structural types, length of span, and thickness of slab in the Slab Construction Method. The Construction Planner may also obtain the reasons for the above results of judgment $\bigcirc, \triangle$, or $X$ of each Slab construction method by referring to the screen that shows the reasons for selecting the construction method, as shown in Fig. 7. This means that the Construction Planner may be informed which conditions should be satisfied for the construction method to be judged applicable. In addition, using the function for referring to the summary of construction methods, information required for examining each Slab construction method might be obtained. This will support selection of suitable construction methods.

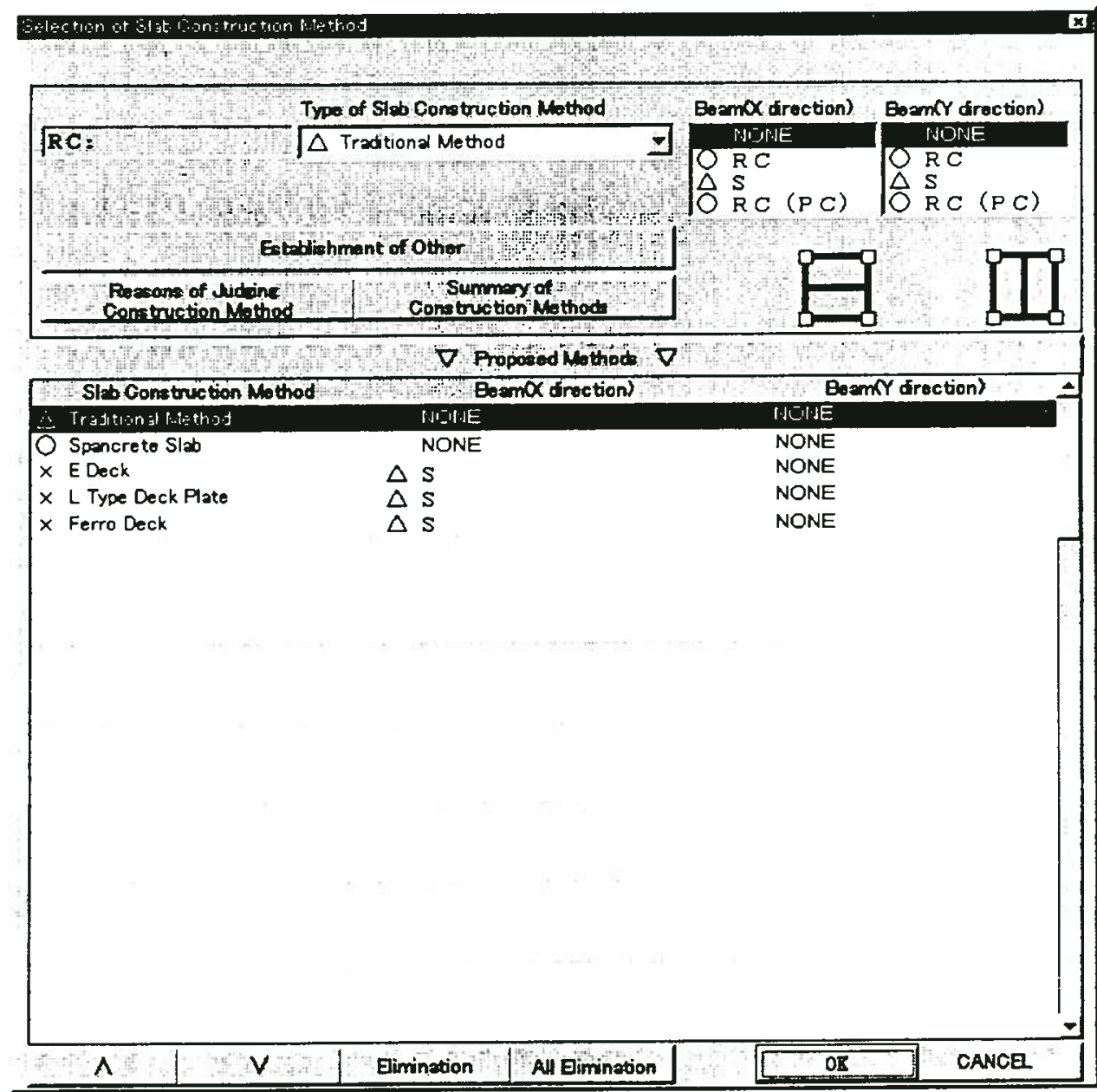

Figure6. The Screen of Selection of Slab Construction Method 


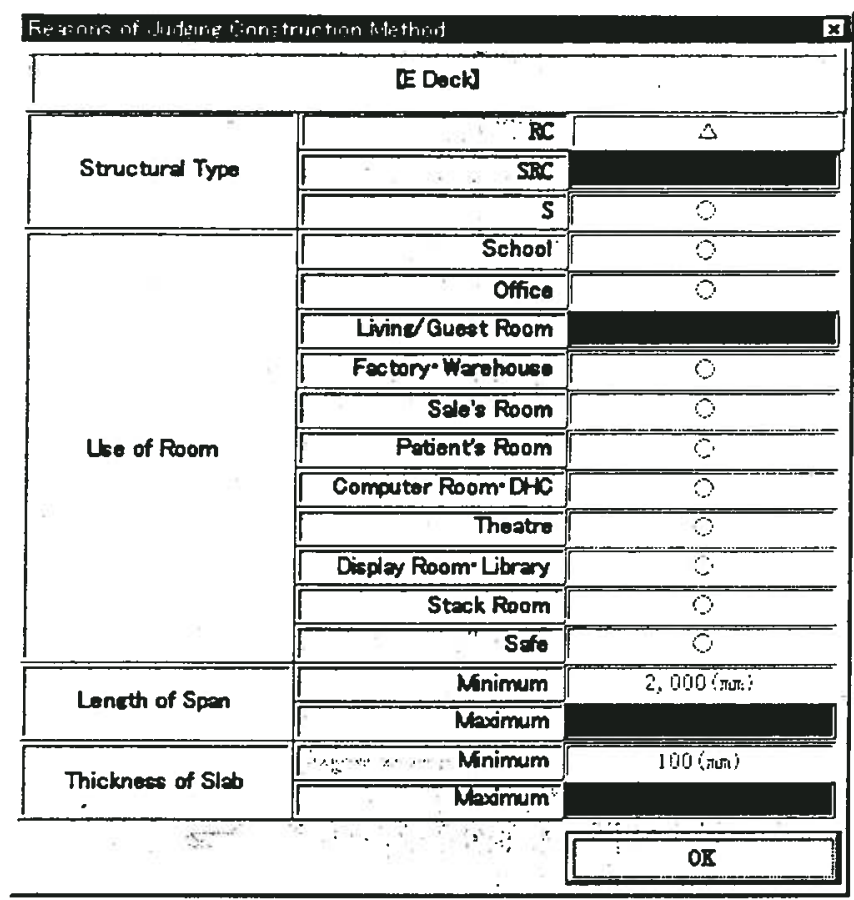

Figure7. The Screen of Reasons of Judging Construction Method

\subsubsection{Calculation of Execution Quantities}

Some combinations of the Slab construction methods which were examined on the basis of the aforesaid judgment of construction methods and the beams will be selected as proposed combinations. For each proposed combination, structural calculations will be automatically made to calculate accurate execution quantities. Fig. 8 shows the screen for calculation results. The calculation process should not be enclosed in a black box, but be disclosed to the Construction Planner so that he may change values and requirements at his own discretion, to the extent that such change is within the design parameters. As a result, for instance, the Construction Planner may adjust the diameter and the pitch of reinforcing bars and number of beams, taking into account workability, to the extent that the adjustment meets the structural characteristics.

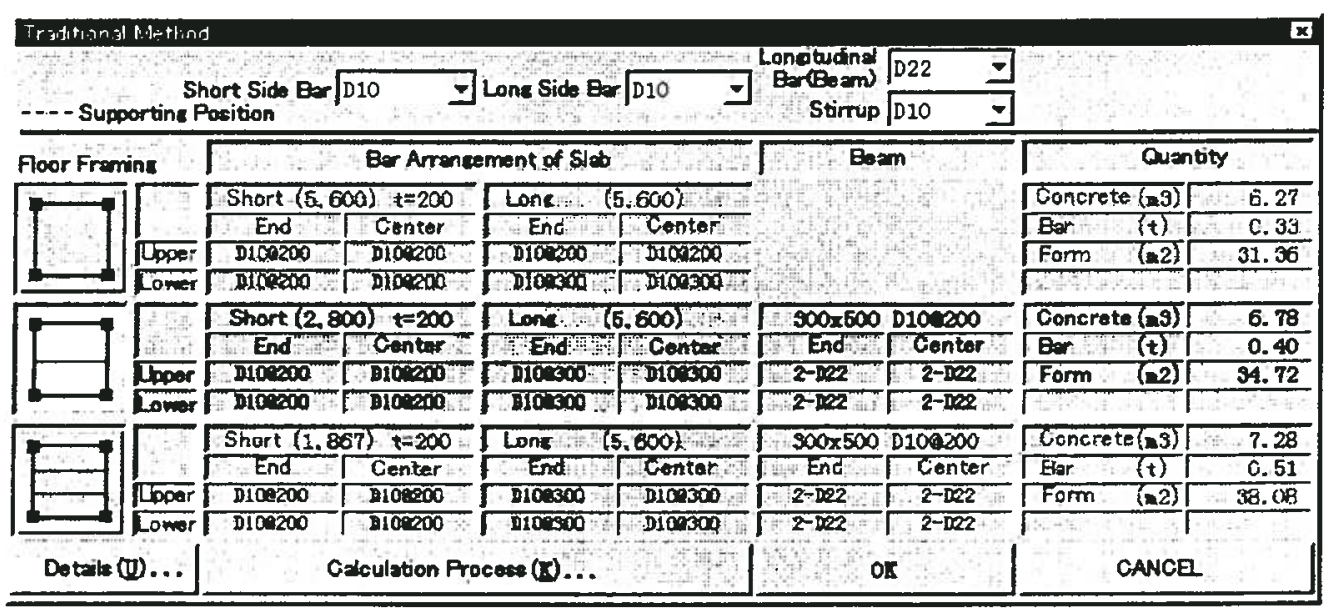

Figure8. The Screen of Structural Calculation Results 


\subsubsection{Preparation of Cost Comparison Table}

Fig. 9 is the cost comparison table to be prepared last. This table consists of a summary and a cost comparison table of floor framing. In the summary of floor framing, examination conditions, section of slab of each construction method, and structural specifications based on the structural calculations are shown automatically. In the cost comparison table, unit cost items are automatically extracted for each construction method from the unit cost database. Up-to-date standard unit costs are used corresponding to the unit cost items extracted. Then construction cost is automatically calculated on the basis of execution quantities. The Construction Planner may make additions to or change these contents of the unit costs to meet the individual conditions of a project. As a result of the comparison of the construction methods based upon revised unit costs and unit cost per bay, the Construction Planner finally decides the Construction Method to be applied in the project. If it is necessary to change these conditions or requirements to re-examine construction methods, any change of conditions may instantly be reflected in the cost comparison table. Accordingly, it is possible to carry out a wide range of re-examinations in a very short time.

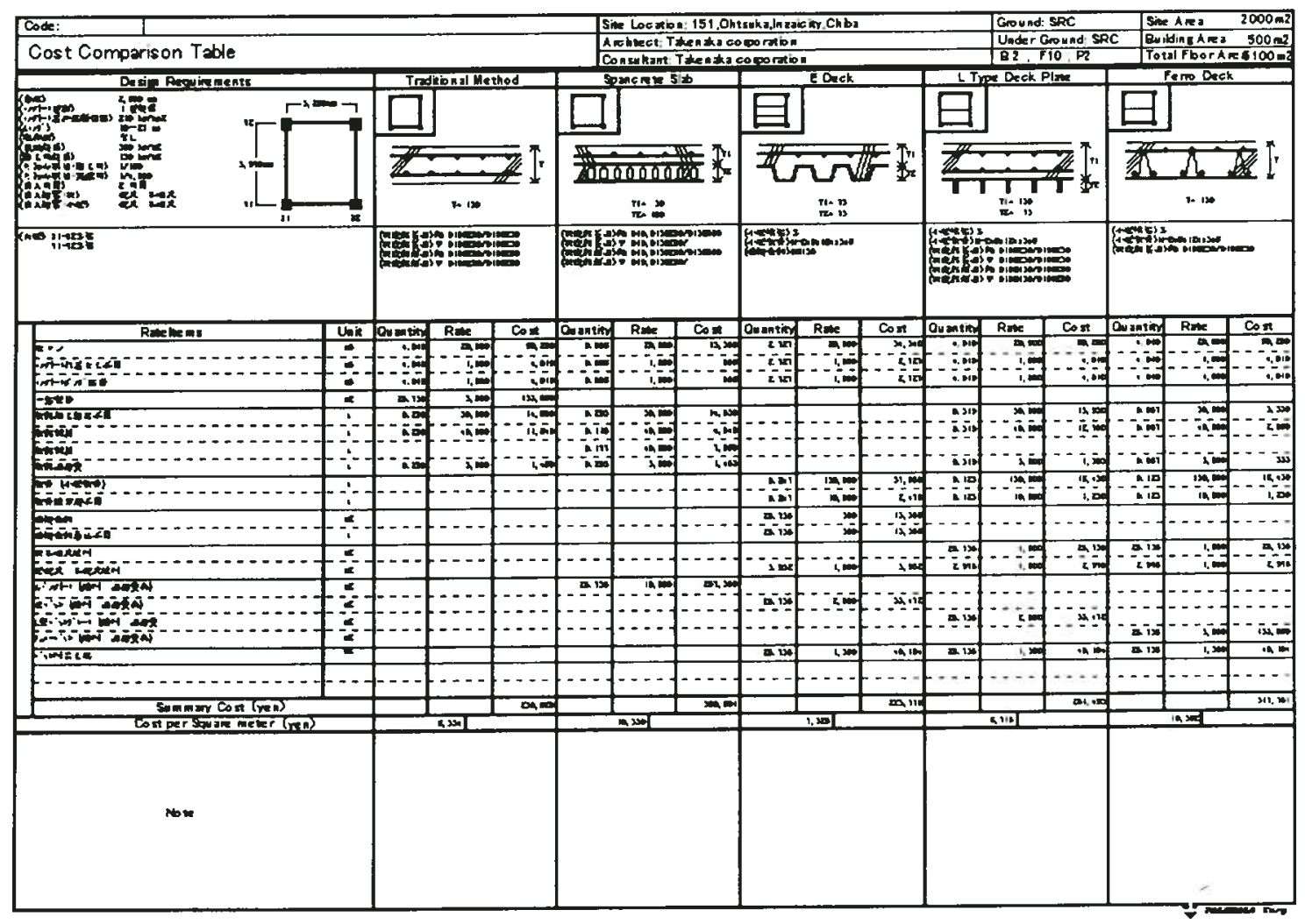

Figure9. The Output of Cost Ccomparison table 


\subsection{MAINTENANCE SYSTEM}

The unit costs necessary for comparing the costs of each construction method are always fluctuating. In addition, the timing of fluctuations differs every unit cost. Every applicable construction method and unit cost in fact differs in different districts where projects are located. Therefore, construction methods and unit costs were saved in the database to meet the actual circumstances. Eventually, this System was established to enable continuous maintenance to be carried out. The System has a device that makes it possible to carry out maintenance for the following two items.

\section{1) Establishment Relating to the Construction Methods}

*Establishment of the Slab construction methods usable in the System

*Establishment of the specified design strength of reinforced concrete

*Establishment of companies dealing in the maintenance

\section{2) Establishment Relating to the Unit Costs}

*Up-to-dating of the unit costs

*Establishment of the time of up-to-dating of each unit cost item

*Establishment of new unit cost items

Maintenance staff is appointed at the stage of using the System. He is the only person who can renew and operate the various databases. As a result, it is expected that information on the construction methods and unit costs will be centralized and better secured.

\subsection{RESULTS OF ACTUALLY USING THE SYSTEM}

The Slab Construction Selection Support System has been applied to 16 projects. As a result, it was ascertained that it is possible to select the optimum Slab construction method from among various Slab construction methods and improve the quality of planning. In fact, the planning work took only about one hour due to the System, while it had taken 11 hours on average before. This shows that time and labor were eliminated or reduced by $90 \%$, thus demonstrating the efficiency of the System.

\section{Conclusion}

This paper demonstrates the overall concept of the Construction Method Selection Support System required for the Construction Method Planning. The Slab Construction Method Selection Support System developed on the basis of the above overall concept is also summarized above. Although the System has just started to be used in ongoing projects, it was fully verified the System provides valuable support for improving the Construction Method Planning and eliminating or reducing time and labor. 